\title{
Epidemiology of Psychiatric Disability in Childhood and Adolescence
}

\author{
Lourdes Ezpeleta \\ Universitat Autònoma de Barcelona, Spain
}

\author{
Gordon Keeler, Alaatin Erkanli, E. Jane Costello, and Adrian Angold \\ Duke University, Durham, U.S.A.
}

\begin{abstract}
The goal of the study was to ascertain the factor structure and prevalence of psychiatric disability in children and adolescents in relation to demographic variables and diagnosis. A representative sample of 1420 children (9-13 years) from 11 countries in North Carolina was followed for up to 6 years. Children and caretakers were interviewed with the Child and Adolescent Psychiatric Assessment, which generates DSM-IV diagnoses and includes a measure of disability secondary to psychological symptoms. Three broad areas of disability were identified (relating to family, school, and peers). School disabilities were more common in boys than girls, while the reverse was true of family disability. Effects of age were complex, and partially gender-differentiated. Children from minority ethnic groups had a higher overall prevalence of school disabilities, and were more prone than Whites to the disabling effects of disruptive behavior disorders. Anxiety disorders were as likely to result in disability as depressive disorders, and oppositional defiant disorders were more strongly associated with disability in some areas than was conduct disorder. The areas where disability is manifested are different depending on race, gender, age, and the type of disorder suffered. The implications of these findings for nosology and prevention are discussed.
\end{abstract}

Keywords: Disability, impairment, functioning, epidemiology, child and adolescent psychopathology.

Abbreviations: ADHD: attention deficit hyperactivity disorder; CAPA: Child and Adolescent Psychiatric Assessment; CD: conduct disorder; CIS: Columbia Impairment Scale; NOS: not otherwise specified; ODD: oppositional defiant disorder; SAICA: Social Adjustment Inventory for Children and Adolescents.

\section{Introduction}

It is well established that psychiatric disorders result in many psychosocial problems, deviations, and limitations in addition to the "symptoms" that are used to establish the nature of the disorder itself (e.g., Bird, Canino, Rubio-Stipec, \& Ribera, 1987; Bird et al., 1990, 1993; Gureje \& Omigbodun, 1995; Hodges \& Cheong-Seok, 2000; Hodges \& Wong, 1996; Verhulst et al., 1993). Indeed, the DSM-IV (American Psychiatric Association, 1994) has gone so far as to require, in its general rubric about the definition of psychiatric disorders (p. xxi), that "disorders" must be associated with distress or what is referred to as "disability" (or increased risk of future disability). Disability is defined here as "impairment in one or more important areas of functioning". Reference to definitions of the specific disorders reveals that these areas are "social, academic (occupational), or other important areas of functioning" (e.g., p. 113). In addition, most of the criteria for the specific disorders also contain mention of the need for the presence of "impairment" or distress. However, as others have noticed (Spitzer \& Wakefield, 1999; Wakefield, 1997), the

Requests for reprints to: Lourdes Ezpeleta, Departament de Psicologia de la Salut i Psicologia Social. Edifici B, Universitat Autònoma de Barcelona, 08193 Bellaterra (Barcelona), Spain (E-mail: lourdes.ezpeleta@uab.es).
DSM-IV is inconsistent in its requirements in relation to disability (impairment) from one part of the manual to another and from disorder to disorder, and its approach raises a host of conceptual, measurement, and methodological problems. For instance, several of the criterion sets for childhood disorders make no mention of distress, disability, or impairment: Rett's syndrome, pica, rumination, feeding disorder of infancy, encopresis, reactive attachment disorder, and three disorders not otherwise specified (NOS) - communication disorders NOS, attention deficit hyperactivity disorder (ADHD) NOS, and tic disorder NOS.

Wakefield has provoked debate in consistently presenting his conceptualization of psychiatric disorders (and medical disorders in general) as "harmful dysfunctions" in opposition to the DSM system. However, his definition shares with the DSM the requirement that the existence of a disorder demands the presence of impairment at the level of the functioning of the whole organism. For instance, he states (Wakefield, 1997, p. 279) "Many things go wrong with various mental and physical mechanisms that do not deserve to be called disorders because they do not have sufficiently negative implications for the individual's overall well-being .... The difference between dysfunctions that can be classified as disorders and dysfunctions that cannot be classified as disorders thus lies in whether the dysfunction causes real harm to the person." 
The classifications of disease and disability developed by the World Health Organization have taken a radically different approach in rigidly separating the concept of the disease from its effects on function. In the latest iterations of these classifications, the tenth revision of the International classification of diseases (ICD-10; World Health Organization, 1993) and the second edition of the International classification of functioning and disability (ICIDH-2; World Health Organization, 2000), the former classifies diseases (which ICIDH-2 calls "health conditions"), by which are meant the disordered mental and bodily processes that may generate disabilities, whereas ICIDH-2 provides a classification scheme for the resulting disabilities. Disabilities involve significant deviation from or loss of "normal" or "expected" functions. Disability may be observed in any of three "dimensions" or "areas of functioning": (1) Body functions and structures, with psychological functions being included as body functions. The ICIDH-2 uses the term "impairment" in relation to body functions and structure (pp. 15-16), noting that impairments are "problems in body function or structure as a significant deviation or loss" (p. 15). Point (12) on p. 16, however, expands this definition somewhat, by noting that there are four possible types of impairment: loss or lack, reduction, addition or excess, and deviation. (2) Activities - the performance of tasks or actions (p. 18). Activity limitations are difficulties an individual may have in the performance of activities. (3) Participation refers to an individual's involvement in life situations. Participation restrictions are problems in the manner or extent of involvement in life situations. The participation dimension differs from the activity dimension in being manifest at the social level, rather than the level of the individual considered regardless of society. Restrictions in participation are, therefore, dependent on factors external to the individual. In earlier versions of the ICIDH-2 (ICIDH-2, WHO, 1994), activities and participations were formally separated into two dimensions. However, the Prefinal Draft reference has collapsed those two dimensions back into one because "differentiating between 'individual' and 'societal' perspectives on the basis of domains has not been possible given international variation and different approaches between (sic) professionals and theoretical frameworks". However, various possible schemes for differentiating between activities and participations are offered in Appendix 3 of the Prefinal Draft. Limitations and restrictions are to be "assessed against a generally accepted population standard. The standard or norm against which an individual's capacity and performance is compared is that of an individual without a similar health condition" (see Üstun \& Chatterji, 1997, for a detailed discussion of the ICIDH2 approach). Although limitations and restrictions have now been lumped together, a new distinction between "capacity" and "performance" has been introduced. The latter simply refers to what an individual actually does in the current environment. "Capacity" refers to what the individual could do in a notional "standard" environment. However, since no internationally relevant "standard" environments have yet been defined (and it is rather hard to see how one would test capacity in a "standard" family environment, for instance), it seems unlikely that psychiatrically useful measures of "capacity" will be available in the foreseeable future.

One great advantage of separating the disease from the disabilities it causes is that it provides a framework for comparisons among disorders with regard to the degree of disability they cause. A good example of the importance of such work for psychiatry is provided by Murray and Lopez' (1996) study of the global burden of disease in terms of "disability-adjusted life years", which demonstrated that psychiatric disorders were among the leading causes of disability worldwide. This is not to say that there are not many practical barriers to be overcome in differentiating disorders and disabilities. The biggest problems lie at the level of the ICIDH-2's impairments of body functions and structures. At present we can only diagnose (i.e. identify) most health conditions on the basis of the impairments they cause. For instance, diabetes is diagnosed on the basis of elevated blood sugar and inadequate insulin response. A major depressive disorder can only be identified in the presence of a substantial impairment of hedonic function. In a sense, we have to infer the presence of the health condition from the presence of impairments. Thus, there are practical difficulties in maintaining the distinction between health conditions and some levels of disability, but doing so as far as is possible is still helpful, because it places the nosology on a footing that will be increasingly productive as we learn more about the causes and consequences of health conditions. We can still maintain the separation between health conditions "inferred" from impairments of function and structure and their resultant activity limitations and participation restrictions, because, even in psychiatry, neither activity limitations nor participation restrictions are logically necessary requirements for making most diagnoses (as Spitzer \& Wakefield, 1999, amply demonstrate in their critique of DSM-IV's practice in this regard). Indeed, several empirical studies have indicated that psychiatric symptoms and measures of what ICIDH2 would call limitations and restrictions tap meaningfully different dimensions of dysfunction, which independently predict a variety of outcomes, including service use and prognosis (Costello, Angold, \& Keeler, 1999; Costello, Angold, Messer, \& Farmer, 1996; Green, Shirk, Hanze, \& Wasntrath, 1994; Hodges \& Wong, 1997; Hodges, Wong, \& Latessa, 1998; Lavigne et al., 1998; Lyons et al., 1997; McArdle \& Gillett, 1997; Settertobulte \& Kolip, 1997; Shaffer et al., 1983; Verhulst et al., 1993). Maintaining a distinction between diagnosis (usually identified on the basis of impairments of psychological functions) and other dimensions of disability also enables us to investigate the interplay between the two (Ezpeleta, Granero, de la Osa, \& Guillamon, 2000; Hodges, Doucette-Gates, \& Liao, 1999) over time, and from a developmental perspective it is far from obvious that we should expect to see unidirectional causal arrows from disorder to disability.

It is interesting to note that the DSM-IV does not include axis I categories for predominantly relational problems, academic problems, or occupational problems, which are key components of the construct of disability according to the content of many disability measures and ICIDH-2. Rather, clinical problems in these areas are separately classified as "other conditions that may be a focus of clinical attention" and given special "V-codes". Although it is nowhere explicitly stated in the DSM-IV, it appears that this allows the coding of "disability without a disorder", a notion that is essentially antithetical to the WHO approach. On the other hand, this placement makes it clear that the presence of disability alone does not constitute a disorder in DSM-IV.

This picture of conceptual disagreement and confusion 
is reflected in the instruments used to measure psychosocial disability or impairment (Canino, Costello, \& Angold, 1999). Some measures include items that overlap substantially with symptoms used in the diagnosis of psychiatric disorders (e.g., the Child and Adolescent Functional Assessment Scale-Hodges \& Wong, 1996), whereas others make every effort to separate the measurement of symptoms from that of activity limitation and participation restriction (e.g., the Child and Adolescent Psychiatric Assessment or the Diagnostic Interview Schedule for Children, version 4-Angold et al., 1995; Shaffer, Fisher, Lucas, Dulcan, \& Schwab-Stone, 2000). Some measures provide simply an overall rating of disability (like the Children's Global Assessment Scale, CGAS - Shaffer et al., 1983), others offer somewhat more molecular assessments of multiple areas of functioning (like the Columbia Impairment Scale, CIS - Bird et al., 1993), while yet others focus in detail on multiple areas of functioning (like the Social Adjustment Inventory for Children and Adolescents, SAICA-John, Davis, Prusoff, \& Warner, 1987).

Given the importance of the relationships between psychiatric symptoms and disability, and the variety of reasonable measures of both constructs, it is remarkable how little work has been done to examine the nature of these relationships across disorders and across different areas of disability. As Riley and colleagues (Riley, Ensminger, Green, \& Kang, 1998) have noted "most studies have focused on a single type of disorder, have relied on limited aspects of social functioning such as school performance, or have used global ratings of function which do not permit us to characterize how aspects of social functioning are differentially impaired in youths with different types of disorder" (p. 621). Using a 10 -factor assessment of social role functioning, these authors found that competence in domestic activities increased with age in 11-17 year-olds, but other competencies were unaffected by age. Disruptive behavior disorders had greater effects on school performance than did emotional disorders, whereas emotional disorders had a greater effect on involvement in social activities. Both emotional and disruptive disorders were more strongly associated with a variety of types of disability in boys than girls.

Our aim in this paper is to examine the organization of activity limitations and participation restrictions in 9-16 year-olds, and the relationships between such disabilities and gender, age, ethnicity, and diagnosis. Though we have pointed out at some length that in the technical language of ICIDH-2, nearly all psychiatric symptoms are "impairments", and so formally speaking "disabilities" in themselves, it would be tedious to keep referring to "activity limitations and participation restrictions". From this point on, therefore, we shall usually refer to such limitations and restrictions simply as "disabilities" to distinguish them from symptoms and diagnoses.

\section{Methods}

\section{Sample}

The Great Smoky Mountains Study (GSMS) is an ongoing, longitudinal study of the development of psychiatric disorders and need for mental health services in rural and urban young people. Full details of the study design can be found elsewhere (Costello, Angold, Burns, et al., 1996). Briefly, a representative sample of 4500 young people, 9-(cohort A), 11-(cohort B), and 13-(cohort C) year-olds, recruited through the Student Information Management System (SIMS) of the public school systems of 11 counties in western North Carolina, was selected using a household equal probability design. A screening questionnaire, consisting mainly of questions about behavioral problems, was administered to a parent (usually the mother), by telephone or in person. All children scoring above a predetermined cut-point designed to select the highest scoring quartile, plus a 1-in-10 random sample of the rest, were recruited for detailed interviews. In addition, an oversample of all 9-, 11-, and 13-year-old American Indian children $(N=431)$ living in the area were recruited for the interview phase: 349 took part in the study. The lower end of the age range was set at 9 years because 8 or 9 years are the youngest ages at which child selfreports of psychiatric symptoms on the diagnostic interview used are reliable. The response rate at the first wave was $80 \%(N$ $=1420$ ). All participants were re-interviewed annually three times (with participation rates of over $80 \%$ at each follow-up). Each age cohort is now being re-interviewed when they reach the ages of 16 and 19. Here we include only data from subjects aged 9-16, involving 5881 observations from 1420 participants.

\section{Measures}

The Child and Adolescent Psychiatric Assessment (CAPA). The CAPA is a psychiatric interview for children aged 9 and above, and their parents, that elicitsinformation about symptoms that contribute to a wide range of diagnoses (Angold \& Costello, 1995, 2000; Angold et al., 1995). The CAPA combines the characteristics of an "interviewer-based" and a "respondent-based" interview. Like respondent-based interviews, the CAPA uses a highly structured protocol, with required questions and probes. However, as in an interviewerbased interview, the onus throughout is on the interviewer to ensure that subjects (1) understand the question being asked; (2) provide clear information on behavior or feelings relevant to the symptom; and (3) have the symptom at a pre-specified level of severity as defined in an extensive glossary. When symptoms are reported, their dates of onset are also collected, to determine whether they meet the symptom overlap and duration criteria for the various DSM diagnoses. A 3month "primary period" is used rather than a longer period, because shorter recall periods are associated with more accurate recall (Angold, Erkanli, Costello, \& Rutter, 1996). Diagnoses and symptom scales are generated by computer algorithms. All diagnoses, except for ADHD, are based on information from both the parent and child. The diagnosis of ADHD is based on reports from the parent interview only, because of the poor validity of child-based ADHD ratings.

Activity limitation and participation restriction secondary to psychiatric symptomatology in 17 areas of functioning related to life at home, at school, and elsewhere were also rated according to a series of definitions and rules specified in the CAPA glossary and the interview schedule. In general, some decrement in actual function had to be described for a positive rating to be given. Note that all these measures refer to level of performance in ICIDH-2 terminology, and not to capacity. After completing the symptom part of the interview, the interviewer reviewed with the subject the areas of positive symptomatology, which were divided into 19 symptom groups (e.g., ADHD symptoms or depressive symptoms). For each area in which symptoms were reported the subject was questioned about whether those symptoms had resulted in disability, and if so, what areas of functioning were affected. Note that there was no requirement that symptoms in any groups should meet any sort of diagnostic criteria. A single symptom could be the basis for an impairment coding related to that symptom's group. Thus impairment resulting from diagnostically "subthreshold" symptoms was often coded. Once a disability had been identified, interviewers were required to question the participants about what aspects of their symptomatology had led to that impairment. However, for the purposes of this paper, we take no account of the respondents' attributions as to the specific causes of their disabilities, basing 
Table 1

Prevalences (and 95\% Confidence Intervals) of Individual Disabilities

\begin{tabular}{lccc}
\hline & $\begin{array}{c}\text { Total } \\
(N=5881)\end{array}$ & $\begin{array}{c}\text { Female } \\
(N=2639)\end{array}$ & $\begin{array}{c}\text { Male } \\
(N=3242)\end{array}$ \\
\hline Parent 1 withdrawal & $1.9(1.5-2.6)$ & $2.6(1.8-3.9)$ & $1.2(0.9-1.8)$ \\
Parent 1 discord & $3.5(2.8-4.3)$ & $3.6(2.7-4.9)$ & $3.3(2.5-4.4)$ \\
Parent 2 withdrawal & $2.6(1.9-3.5)$ & $2.6(1.8-3.8)$ & $2.6(1.6-4.1)$ \\
Parent 2 discord & $2.1(1.4-2.9)$ & $1.8(1.2-2.7)$ & $2.3(1.3-4.0)$ \\
Other parent 1 withdrawal & $7.3(5.8-9.4)$ & $9.0(6.5-12.4)$ & $6.1(4.3-8.5)$ \\
Other parent 1 discord & $2.4(1.7-3.4)$ & $3.5(2.2-5.5)$ & $1.5(0.9-2.5)$ \\
Other parent 2 withdrawal & $1.8(1.3-2.5)$ & $2.8(1.9-4.1)$ & $1.0(0.6-1.7)$ \\
Other parent 2 discord & $0.6(0.4-1.0)$ & $0.8(0.4-1.5)$ & $0.5(0.2-0.9)$ \\
Siblings withdrawal in house & $2.5(1.9-3.3)$ & $2.3(1.6-3.4)$ & $2.7(1.8-4.0)$ \\
Siblings discord in house & $3.7(2.8-4.9)$ & $3.2(2.1-4.8)$ & $2.7(1.8-4.0)$ \\
Siblings withdrawal out & $1.0(0.6-1.4)$ & $1.1(0.6-1.9)$ & $0.8(0.4-1.6)$ \\
Siblings discord out & $0.5(0.3-0.8)$ & $0.5(0.3-0.9)$ & $0.6(0.3-1.3)$ \\
Self-care & $0.2(0.1-0.3)$ & $0.2(0.1-0.3)$ & $0.3(0.1-0.5)$ \\
Chores & $2.4(1.9-3.1)$ & $2.3(1.6-3.4)$ & $2.6(1.9-3.4)$ \\
Homework & $2.9(2.3-3.6)$ & $1.9(1.2-3.0)$ & $3.8(2.9-5.0)$ \\
Leaving house & $0.7(0.5-1.1)$ & $0.7(0.3-1.3)$ & $0.8(0.4-1.4)$ \\
Spare time & $0.7(0.4-1.1)$ & $0.8(0.5-1.6)$ & $0.5(0.3-1.0)$ \\
School performance & $3.5(2.8-4.4)$ & $2.8(1.9-4.1)$ & $4.2(3.3-5.4)$ \\
Teacher withdrawal & $1.0(0.7-1.6)$ & $0.4(0.2-0.6)$ & $1.7(1.0-2.9)$ \\
Teacher discord & $2.0(1.5-2.7)$ & $0.9(0.5-1.5)$ & $3.1(2.2-4.5)$ \\
Peer withdrawal in school & $1.7(1.2-2.3)$ & $2.0(1.2-3.2)$ & $1.4(1.0-2.0)$ \\
Peer discord in school & $1.5(1.2-2.0)$ & $1.1(0.7-1.8)$ & $1.9(1.4-2.6)$ \\
Employment withdrawal & $0.2(0.1-0.4)$ & $0.1(<0.1-0.1)$ & $0.3(0.1-0.7)$ \\
Employment discord & $0.2(0.1-0.4)$ & $<0.1(0.1-0.2)$ & $0.3(0.1-0.7)$ \\
Suspension/expulsion & $9.4(8.0-11.0)$ & $4.5(3.4-5.9)$ & $14.3(11.9-17.1)$ \\
Relationship adult withdrawal & $0.2(0.1-0.4)$ & $0.2(0.1-0.7)$ & $0.2(0.1-0.3)$ \\
Relationship adult discord & $0.2(0.1-0.3)$ & $0.2(0.1-0.3)$ & $0.2(0.1-0.3)$ \\
Relationship peer withdrawal & $1.2(0.8-1.7)$ & $1.2(0.7-2.1)$ & $1.2(0.8-1.8)$ \\
Relationship peer discord & $1.1(0.8-1.6)$ & $0.8(0.5-1.3)$ & $1.4(0.9-2.2)$ \\
\hline & & &
\end{tabular}

our analyses solely upon whether a disability due to any symptomatology was reported. This scheme meant that it was impossible to have a disability without symptomatology to which the symptomatology was attributable. We have reported on "pure" relationship problems (unattributable to any other symptomatology) elsewhere (Angold, Costello, Farmer, Burns, \& Erkanli, 1999), but they are not included here. It is debatable whether or not "pure" activity limitations and participation restrictions (in the absence of recognized symptoms of disorder) should be included in psychiatric nosologies. The DSM-IV has a section called "other conditions that may be a focus of clinical attention" (with special V-codes) for such situations. We agree that it is best not to treat such "conditions" as disorders (for classificatory purposes) at the present time.

For relationship disabilities (e.g., problems with parental or sibling relationships) an additional code indicated whether the problem involved withdrawal (refusal or inability to be involved with, or to engage in normal social relationships with others) or discord (involving aggression, arguments, fights, or disruptive behavior). Table 1 shows the resulting 29 possible types of disability that resulted. At this point it may seem that these "disabilities" are largely restatements of what would elsewhere in the interview count as symptoms of various disorders. An example will serve to show the distinction between symptoms and disability. The CAPA's definition of a disability related to peer relationships at school requires: "Decrease in the subject's ability to form mutually interested relationships and to undertake activities with peers at school, including chatting and hanging out. Includes loss of friends or withdrawal from peer activities." Consider now two boys who get into physical fights with their peers a couple of times a week. Both children would receive exactly the same symptom coding as far as fighting is concerned. However, suppose that the first child was part of a rambunctious, troublesome peer group that delighted in mayhem, that his behavior simply mirrored that of his companions, and that his friends continued to associate with him, while occasionally giving him a black eye. Such a child would not be regarded as having any disability in his peer relationships. However, the second boy, whose friends were repelled by his behavior, and began to avoid him, would be regarded as having a disability (in conformity with the ICIDH-2's conceptualization of participation restriction). The symptom coding relates simply to the form and frequency of the behavior (in this case fighting), the disability relates to the effects of the symptom on the child's ability to function in the peer group. Note also that, in this case, the child's level of disability is dependent on the response from his peers, not just on the characteristics of his behavior. The incorporation of this sort of interaction between the characteristics of the individual and the characteristics of the environment in generating disability is also in line with the ICIDH-2's conceptualization of participation restriction. However, activity limitations may have little to do with environmental characteristics, as with a child who is too frightened ever to go out with friends, no matter how hard they may try to get him to take part in their activities. Such an activity limitation would be coded as being a disability involving withdrawal from peer relationships. Similar principles underlie all the disability ratings in the CAPA.

The test-retest intraclass correlation for level of disability measured by the CAPA was .76. Diagnostic 1-week test-retest reliabilities (Kappas) for child self-reports were .55 for conduct disorder, .90 for major depression, .85 for dysthymia, .74 for overanxious disorder, .79 for generalized anxiety disorder, 1.0 for substance abuse/dependence, and .64 for PSTD (Angold \& Costello, 1995; Costello, Angold, March, \& Fairbank, 1998). The construct validity of the CAPA has been well supported (Angold \& Costello, 2000).

\section{Statistical Analysis}

For data reduction purposes we employed a factor analytic approach. Most factor analytic studies of scale scores have used principal components analysis or principal factor analysis, 
both of which rest upon the assumption that scores on the individual items making up the scale are normally distributed. Our $0 / 1$ scored disability data grossly violated this assumption (as do most psychopathology scales, see, e.g., Verhulst, Akkerhuis, \& Althaus, 1985). Our solution to this problem was to use Mplus's (Muthén, 1978, 1983, 1984, 1989) approach to fitting factor models based on dichotomous items. The items are assumed to have been derived from an underlying normal distribution with a superimposed cut-point. The tetrachoric correlation matrix is analyzed and a weighted least squares approach is used to estimate the factor structure, with the asymptotic variance-covariance matrix of the tetrachoric correlations serving as the weight matrix. We also needed to correct the estimates and standard errors for the fact that we had a stratified sampling design, so weighted analyses were employed with robust standard errors. However, we had to conduct these analyses separately for each wave of data collection, because it was not possible to carry out an exploratory (or confirmatory) factor analysis that properly accounted for the effects of repeated measurement.

For analyses involving multiple waves of data (such as logistic regressions with diagnoses as predictors) we needed to correct for both the presence of repeated measures and the screen stratified sampling, so again we required the use of weighted analyses to generate unbiased population parameter estimates and of "sandwich"-type variance corrections (Diggle, Liang, \& Zeger, 1994; Pickles, Dunn, \& Vazquez-Barquero, $1995)$ to produce appropriate confidence intervals and $p$ values. For many analyses these were obtained using generalized estimating equations (GEE) implemented through SAS PROC GENMOD using an unstructured correlation matrix.

\section{Results}

Table 1 shows the prevalence of each individual area of disability. Around a quarter of all children had a disability of some sort.

\section{Exploratory Factor Analyses}

We fit separate exploratory factor analytic models for each of the first four waves of data (since these were the waves in which all participants were represented). Items with less than $1 \%$ prevalence were excluded from the factor analyses, since the inclusion of very uncommon items is liable to cause technical difficulties in reaching satisfactory solutions. Figure 1 shows scree plots for the first four waves, in which all the subjects were seen (including just the first seven eigenvalues). The four scree plots are strikingly similar, and all have a predominant first factor. So a cause can be made that a single-factor solution is appropriate. Table 2 shows the unstandardized factor loadings from such a solution for each wave. All items load appreciably (and most load very highly) on this single factor at all waves. As a result, Cronbach's coefficient alpha for the scales resulting from simply summing the item scores was .72 at wave $1, .71$ at wave 2 , .67 at wave 3, and .69 at wave 4 .

Overall fit statistics suggested that between four and seven factors could be fit to the data, depending on the wave. However, examination of solutions with two or with four or more factors showed that the content of the factors varied from wave to wave, and that higher numbered factors often consisted of only one or two items. Details of these solutions can be obtained from the first author. The scree plots in Fig. 1 also provide no support for the existence of more than three factors. The three-factor solutions were most consistent and interpretable (though they also showed a good deal of variation), and so we report further on these here. Table

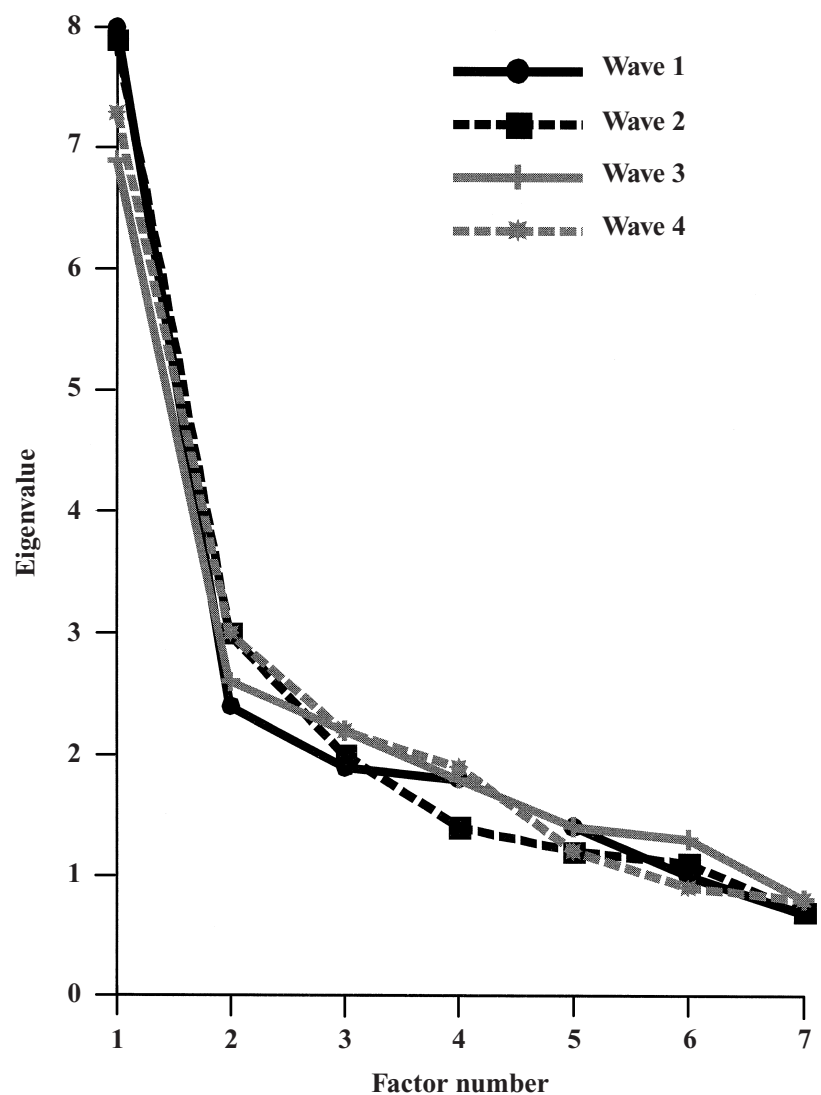

Figure 1. Scree plots from exploratory factor analyses.

3 shows the item loadings on the first three factors following promax rotation. An oblique rotation was used because we could see from the single-factor solution that all the items were positively correlated. Item loadings greater than .4 are indicated in italic type.

Several points of similarity emerge from these four data waves.

(1) Items concerning parents in the home all loaded highly on the first factor in all four solutions.

(2) Relations with parents living out of the home also loaded most highly on this first factor at wave 2 and wave 4. At wave 3 these items had no high positive loadings on any factor. At wave 1 , they were part of a factor that also involved problems with sibling relationships.

(3) Peer and sibling relationship problem items all loaded together on a separate factor at wave 1 (factor 3), wave 2 (factor 2) and wave 4 (factor 3). At wave 3 they loaded together with parental relationship items on factor 1 .

(4) Problems with school performance, homework, relationships with teachers, and suspensions/ expulsions loaded together on a separate factor at wave 4 (factor 2), wave 2 (factor 3 ), and wave 3 (factor 3). At wave 1, they all loaded most highly on factor 1 (with parental relationship problems), except for withdrawal from teachers.

(5) Problems with chores had their highest loading at wave 1 and 3 , when they accompanied parental relationship problems. At waves 2 and 4, this item was most highly associated with peer/sibling problems and school problems respectively. At wave 3 , however, parental relationship problems also loaded highly on this factor (factor 1). 
Table 2

Unstandardized Factor Loadings from Single Factor Solutions

\begin{tabular}{lcccc}
\hline & Wave 1 & Wave 2 & Wave 3 & Wave 4 \\
\hline Parent 1 withdrawal & .63 & .81 & .80 & .90 \\
Parent 1 discord & .66 & .79 & .76 & .77 \\
Parent 2 withdrawal & .77 & .71 & .34 & .45 \\
Parent 2 discord & .78 & .57 & .40 & .60 \\
Other parent 1 withdrawal & .63 & .61 & .80 & .70 \\
Other parent 1 discord & .78 & .79 & .84 & .70 \\
Relationship siblings withdrawal & .98 & .96 & 1.0 & .87 \\
Relationship siblings discord & .92 & .94 & .91 & .99 \\
Chores & .62 & .45 & .54 & .59 \\
Homework & .61 & .71 & .63 & .75 \\
School performance & .74 & .75 & .82 & .91 \\
Teacher relationship withdrawal & .81 & .83 & .79 & .82 \\
Teacher relationship discord & .78 & .85 & .65 & .80 \\
Peers withdrawal in school & .89 & .56 & .71 & .56 \\
Peers discord in school & .83 & .42 & .88 & .75 \\
Other peers withdrawal & .95 & .77 & .31 & .80 \\
Other peers discord & .83 & .86 & .73 & .79 \\
School suspensions/expulsions & .56 & .56 & .46 & .54 \\
\hline
\end{tabular}

Table 3

Unstandardized Factor Loadings from Three-factor Solutions ${ }^{\mathrm{a}}$

\begin{tabular}{|c|c|c|c|c|c|c|c|c|c|c|c|c|}
\hline & \multicolumn{3}{|c|}{ Wave 1} & \multicolumn{3}{|c|}{ Wave 2} & \multicolumn{3}{|c|}{ Wave 3} & \multicolumn{3}{|c|}{ Wave 4} \\
\hline & $\mathrm{F} 1$ & $\mathrm{~F} 2$ & $\mathrm{~F} 3$ & $\mathrm{~F} 1$ & $\mathrm{~F} 2$ & F3 & $\mathrm{F} 1$ & $\mathrm{~F} 2$ & F3 & $\mathrm{F} 1$ & $\mathrm{~F} 2$ & F3 \\
\hline Parent 1 withdrawal & .71 & .17 & -.06 & .82 & .15 & .21 & .79 & .24 & .20 & .61 & .58 & -.06 \\
\hline Parent 1 discord & .78 & .12 & -.05 & .70 & .21 & .20 & .79 & .09 & .16 & .42 & .60 & .00 \\
\hline Parent 2 withdrawal & .75 & -.21 & .25 & 1.0 & -.34 & .27 & .73 & .25 & .05 & .86 & -.10 & -.03 \\
\hline Parent 2 discord & .99 & -.31 & -.04 & .74 & -.05 & .14 & .75 & .12 & .04 & .96 & .10 & -.13 \\
\hline Other parent 1 withdrawal & -.01 & .85 & -.16 & .52 & .44 & -.51 & -.19 & -1.10 & .35 & .88 & -.19 & .15 \\
\hline Other parent 1 discord & .07 & .95 & -.32 & .71 & .43 & -.47 & .01 & -.81 & .15 & .98 & -.05 & -.08 \\
\hline Rel. sibling house withdrawal & -.24 & .64 & .88 & .12 & .85 & .20 & .83 & -.59 & -.37 & .00 & -.21 & 1.06 \\
\hline Rel. sibling house discord & -.14 & .51 & .81 & .13 & .83 & .21 & .82 & -.48 & -.28 & .05 & -.15 & .99 \\
\hline Chores & .64 & .16 & .05 & .33 & .35 & .04 & .62 & .16 & .12 & .27 & .40 & .21 \\
\hline Homework & .80 & -.03 & -.07 & .18 & .12 & .72 & .18 & .05 & .64 & -.12 & .84 & .06 \\
\hline School & .69 & .18 & .15 & .31 & .07 & .73 & .18 & -.00 & .88 & .00 & 1.05 & -.14 \\
\hline Teacher withdrawal & .37 & .64 & .29 & -.10 & .24 & .97 & -.04 & -.23 & .90 & -.11 & .94 & -.11 \\
\hline Teacher discord & .70 & .36 & .05 & .02 & .19 & .82 & .01 & -.13 & .77 & .17 & .81 & -.06 \\
\hline Peers withdrawal in school & .14 & -.20 & .86 & -.29 & .63 & .35 & .55 & -.15 & .36 & -.16 & .05 & .89 \\
\hline Peers discord in school & .17 & -.17 & .82 & -.39 & .61 & .46 & .67 & -.10 & .42 & -.18 & .11 & .92 \\
\hline Other peers withdrawal & .12 & -.15 & .92 & .06 & .82 & .00 & .59 & .01 & .02 & .26 & .42 & .52 \\
\hline Other peers discord & .12 & -.13 & .86 & .12 & .91 & -.02 & .72 & -.20 & .15 & .26 & .38 & .48 \\
\hline Expulsions/suspensions & .44 & .34 & .09 & .30 & -.14 & .71 & .10 & .00 & .57 & -.35 & .81 & .04 \\
\hline
\end{tabular}

${ }^{\mathrm{a}}$ Item loadings greater than .4 are in italic.

(6) There was no evidence at all for separate dimensions of "withdrawal" and "discord" among the relationship disabilities.

Our best summary of the overall meaning of these results is that there are three basic dimensions of disability tapped by our measures: (1) parent disabilities, (2) peer disabilities, and (3) educational disabilities. For further analysis, therefore, we created three disability categories characterized by the presence of one or more disabilities belonging to each of these dimensions, plus an overall disability category, as follows:

(1) Parent disabilities - the presence of one or more disabilities relating to parents (withdrawal or discord), whether living with the child or not, plus problems with chores.

(2) Peer disabilities - the presence of one or more disabilities in sibling or peer relationship (withdrawal or discord).
(3) Educational disabilities - the presence of one or more of the following; teacher relationship disabilities (withdrawal or discord), homework problems, disability in school performance, and suspension/expulsion.

(4) Any disability - the presence of any of the above.

These were nonexclusive categories, so an individual child could belong to all of them if she or he had disabilities in each category.

\section{Effects of Demographic Characteristics}

We next examined the effects of demographic characteristics and diagnostic status on membership in these four categories.

Ethnicity. Thirty-one per cent of observations were from minority respondents (the vast majority were American Indian or African American). These respondents were somewhat more likely to report the 
Table 4

Effects of Gender and Race on Disability Groupings (95\% CI in parentheses)

\begin{tabular}{|c|c|c|c|c|c|c|c|}
\hline & $\begin{array}{l}\text { Total sample } \\
\text { prevalence }\end{array}$ & $\begin{array}{c}\text { Female } \\
\text { prevalence }\end{array}$ & $\begin{array}{c}\text { Male } \\
\text { prevalence }\end{array}$ & OR & $\begin{array}{l}\text { Whites } \\
\text { prevalence }\end{array}$ & $\begin{array}{l}\text { Minority } \\
\text { prevalence }\end{array}$ & OR \\
\hline$N$ & 5881 & 2639 & 3242 & & 4062 & 1819 & \\
\hline Any disability & $\begin{array}{c}27.3 \\
(24.8-29.9)\end{array}$ & $\begin{array}{c}24.7 \\
(21.2-28.6)\end{array}$ & $\begin{array}{c}30.1 \\
(26.8-33.6)\end{array}$ & $\begin{array}{c}1.3^{*} \\
(1.02-1.7)\end{array}$ & $\begin{array}{c}26.6 \\
(24.0-29.5)\end{array}$ & $\begin{array}{c}31.6 \\
(25.4-38.6)\end{array}$ & $\begin{array}{c}1.4 \\
(0.9-1.6)\end{array}$ \\
\hline Family & $\begin{array}{c}13.8 \\
(11.8-15.8)\end{array}$ & $\begin{array}{c}15.7 \\
(12.7-18.7)\end{array}$ & $\begin{array}{c}12.2 \\
(9.8-14.6)\end{array}$ & $\begin{array}{c}0.8 \\
(0.6-1.04)\end{array}$ & $\begin{array}{c}14.1 \\
(11.9-16.3)\end{array}$ & $\begin{array}{c}11.4 \\
(8.7-14.1)\end{array}$ & $\begin{array}{c}0.8 \\
(0.6-1.1)\end{array}$ \\
\hline Educational & $\begin{array}{c}12.7 \\
(11.0-14.4)\end{array}$ & $\begin{array}{c}7.3 \\
(5.6-9.1)\end{array}$ & $\begin{array}{c}17.9 \\
(15.1-20.6)\end{array}$ & $\begin{array}{c}2.9 * * * \\
(2.1-3.9)\end{array}$ & $\begin{array}{c}11.5 \\
(9.8-13.3)\end{array}$ & $\begin{array}{c}22.7 \\
(17.7-27.7)\end{array}$ & $\begin{array}{c}2.0 * * * \\
(1.7-3.3)\end{array}$ \\
\hline Peers & $\begin{array}{c}6.2 \\
(5.0-7.4)\end{array}$ & $\begin{array}{c}6.0 \\
(4.3-7.7)\end{array}$ & $\begin{array}{c}6.4 \\
(4.7-8.2)\end{array}$ & $\begin{array}{c}1.0 \\
(0.7-1.6)\end{array}$ & $\begin{array}{c}5.8 \\
(4.6-7.1)\end{array}$ & $\begin{array}{c}9.1 \\
(5.2-13.1)\end{array}$ & $\begin{array}{c}1.7 \\
1.7(0.9-2.5)\end{array}$ \\
\hline
\end{tabular}

$* p<.05 ; * * p<.01 ; * * * p<.001$.

presence of some disability (Table 4). This was accounted for by minority participants' higher probabilities of having school and peer disabilities. They were not more likely to have family disabilities.

Gender. Table 4 also shows the weighted prevalences (and their confidence intervals) of each type of impairment by sex, with the odds ratios (OR) for comparisons between boys and girls (with boys coded 1 and girls coded 0 ). There was a $30 \%$ excess of any disability in boys, entirely accounted for by the presence of much higher rates of educational disabilities in the boys. In boys, educational disabilities were the most common form, whereas in girls family disabilities were most common. On the basis of this finding, and because rates of specific disorders are substantially gender differentiated, we decided to conduct further analyses separately by gender.

Age. Figures 2 and 3 show the prevalences of disabilities by age for girls and boys respectively. To describe the shapes of these curves statistically, we first fit cubic logistic models of age to the probability of disability (see Table 5, $\mathrm{Age}^{3}$ ). If the quadratic and cubic terms were significant at the .05 level, we retained this model. Otherwise, we fit a quadratic model, and retained that if the quadratic term was significant (Table 5, $\mathrm{Age}^{2}$ ). If it was not, we then tested a linear model. Given that complex age relationships emerged for several areas, we also plotted and inspected the predicted values from the regressions (not shown) to ensure that they were good representations of the raw data. The shapes of the age curves for the presence of any disability were similar in boys and girls, with an initial fall from age 9-12 followed by substantial increases through early to mid adolescence, with a final fall-off by age 16. In both boys and girls the relationship between age and school disabilities showed roughly similar sigmoid patterns (though with greater amplitude in the boys). However, the changes in the other subgroups of disabilities underlying this overall pattern were rather different in boys and girls. With respect to family disabilities, girls showed substantial age effects similar in form to those just described. However, in boys there was no significant effect of age. With respect to peer relationship disabilities, there was no significant relationship with age in girls, but a small linear reduction with age in boys.

Contemporaneous relationships between symptomatic diagnoses and disability. The prevalence of any disorder in the sample was $12.9 \%$. Of these, $41.8 \%$ children had just diagnoses without disability and $58.2 \%$ had at least one diagnosis plus disability. Twenty-seven per cent of the total sample had one or more areas of disability. Of these, $72.2 \%$ had just disability without diagnosis and $27.8 \%$ disability with a diagnosis. Figure 4 shows the prevalence of disability in the studied areas in different diagnostic groups. Depression and conduct disorder were the disorders with highest frequencies of disability.

Table 6 shows the results of the logistic regression models of the relationships between diagnoses and disabilities. We wanted to determine whether gender or minority status affected the probability of having disability in relation to each disorder, so we began with models that included these factors as main effects plus the 12 possible two-way interactions involving diagnosis, gender, and minority status. We then progressively deleted nonsignificant $(p>.05)$ interactions. Once only significant interactions remained, we added each previously eliminated interaction individually to ensure that no important interactions had been inappropriately eliminated earlier in the process. As a final step, we removed any nonsignificant diagnostic main effects (that were also not associated with any significant interaction) to check that collinearity included by diagnostic comorbidity had not had a substantial effect on the results. In no case was there a problem in this regard, so in the models reported here nonsignificant effects of diagnosis and minority status remain in the models to facilitate comparisons among them. Note that since the various diagnoses were modeled simultaneously, the ORs represent the independent contribution of each diagnosis, controlling for the presence of the other diagnoses having significant effects on the probability of disability.

All diagnoses had significant independent effects on the probability of having family, school, or any disabilities, though the interpretation of the main effects for ADHD were complicated by the presence of interactions with majority status. In the case of peer disabilities, depression and ODD were significantly related to disability, but anxiety, ADHD, and problematic substance use were not, while there was a significant interaction between CD and minority status.

In no case was there a significant interaction between gender and minority status, so minority status can be said to have affected boys and girls equally. However, there were several interaction effects involving minority status and one or other of the disruptive behavior disorders. All of these effects involved the presence of stronger relationships between disorder and disability in minority participants than in majority participants. This means that, given the disorder, minority participants were more likely to be disabled than majority participants. Of 12 possible interactions of minority status with conduct disorder (CD), oppositional defiant disorder (ODD), or 


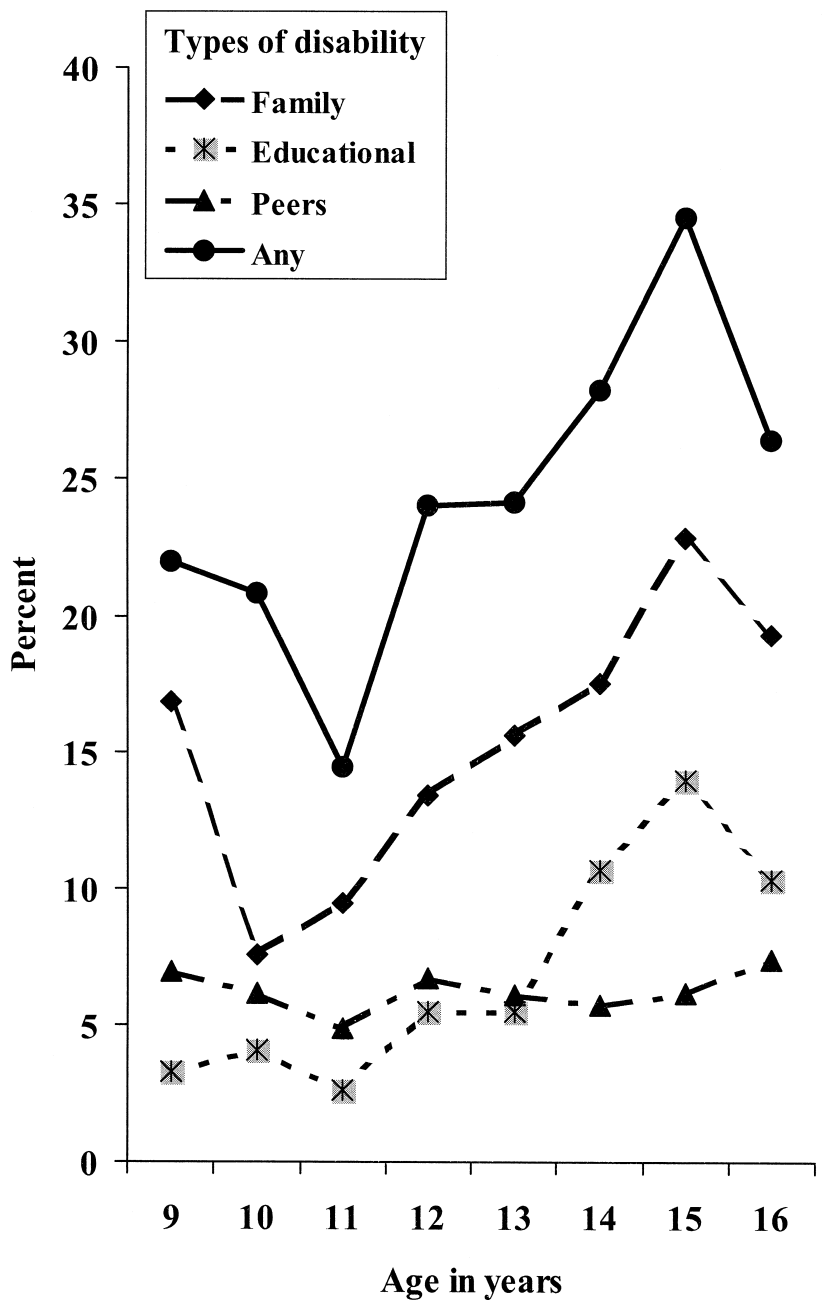

Figure 2. Effects of age on disabilities in girls.

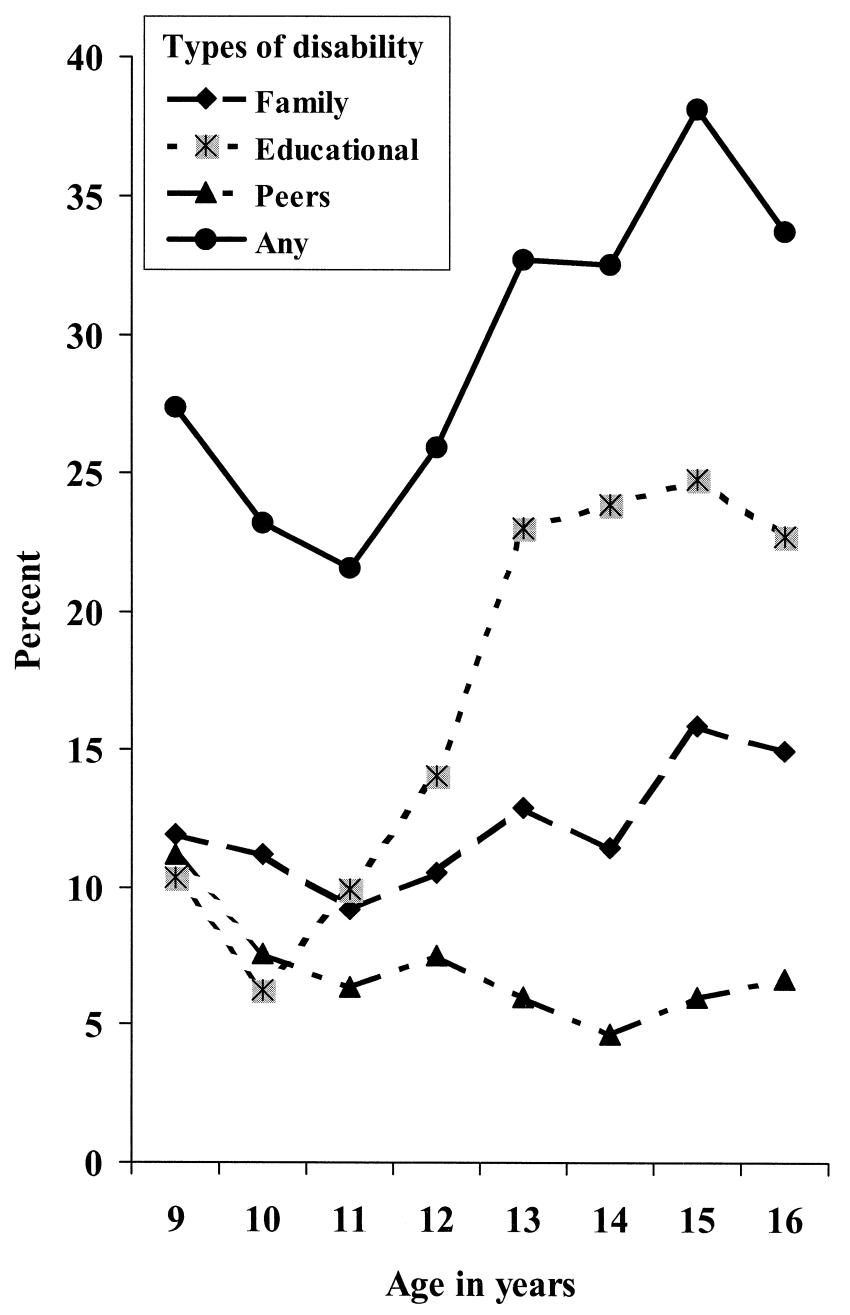

Figure 3. Effects of age on disabilities in boys.

Table 5

Effects of Age on Disability

\begin{tabular}{|c|c|c|c|c|c|c|}
\hline & \multicolumn{3}{|c|}{ Girls } & \multicolumn{3}{|c|}{ Boys } \\
\hline & $\begin{array}{c}\text { Age } \\
\text { OR }(95 \% \mathrm{CI})\end{array}$ & $\begin{array}{c}\text { Age }^{2} \\
\text { OR }(95 \% \mathrm{CI})\end{array}$ & $\begin{array}{c}\text { Age }^{3} \\
\text { OR }(95 \% \mathrm{CI})\end{array}$ & $\begin{array}{c}\text { Age } \\
\text { OR }(95 \% \mathrm{CI})\end{array}$ & $\begin{array}{c}\text { Age }^{2} \\
\text { OR }(95 \% \mathrm{CI})\end{array}$ & $\begin{array}{c}\mathrm{Age}^{3} \\
\text { OR }(95 \% \mathrm{CI})\end{array}$ \\
\hline Any incapacity & $\begin{array}{c}0.0004 * * * \\
(0.00-0.01)\end{array}$ & $\begin{array}{c}2.27 * * * \\
(1.42-3.62)\end{array}$ & $\begin{array}{c}0.98 * * * \\
(0.97-0.99)\end{array}$ & $\begin{array}{c}0.0000^{*} \\
(0.00-0.35)\end{array}$ & $\begin{array}{c}1.79 * \\
(1.09-2.9)\end{array}$ & $\begin{array}{c}0.98^{*} \\
(0.97-0.99)\end{array}$ \\
\hline Family & $\begin{array}{c}0.0000 * * * \\
(0.00-0.18)\end{array}$ & $\begin{array}{c}2.78 * * * \\
(1.55-4.97)\end{array}$ & $\begin{array}{c}0.97 * * * \\
(0.96-0.99)\end{array}$ & n.s. & n.s. & n.s. \\
\hline Educational & $\begin{array}{c}0.00002^{*} \\
(0.00-0.40)\end{array}$ & $\begin{array}{c}2.46^{*} \\
(1.10-5.50)\end{array}$ & $\begin{array}{c}0.98^{*} \\
(0.96-0.99)\end{array}$ & $\begin{array}{c}0.0003^{*} \\
(0.00-0.85)\end{array}$ & $\begin{array}{c}2.00^{*} \\
(1.06-3.79)\end{array}$ & $\begin{array}{c}0.98^{*} \\
(0.97-0.99)\end{array}$ \\
\hline Peers & n.s. & n.s. & n.s. & $\begin{array}{c}0.88^{*} \\
(0.78-0.99)\end{array}$ & n.s. & n.s. \\
\hline
\end{tabular}

$* p<.05 ; * * p<.01 ; * * * p<.001$.

ADHD, 6 were statistically significant (and of larger magnitude). Three of the nonsignificant interactions went in the same direction as the significant interaction, whereas three went in the opposite direction, the largest of which was the difference between ORs of 3.6 (majority) and 1.5 (minority) for effects of CD on school disability. The other two differences in ORs were 0.6 or less.

One possible explanation for the presence of higher rates of disability in minority participants with disruptive behavior disorders is that their disorders might be more symptomatic than those of majority participants. We therefore generated counts of disruptive behavior disorder symptoms, and compared those counts for the minority and majority participants. The disruptive behavior disordered minority participants actually had nonsignificantly lower symptoms counts $($ mean $=8.4$ ) compared with the majority participants (mean $=9.4$; $p$ for difference $=.3$ ). So the minority children's higher risk for disability cannot be explained by their having more symptoms.

\section{Discussion}

Although hundreds of studies have examine the patterns of relationships among the symptoms of psychiatric disorders in children and adolescents, there are 


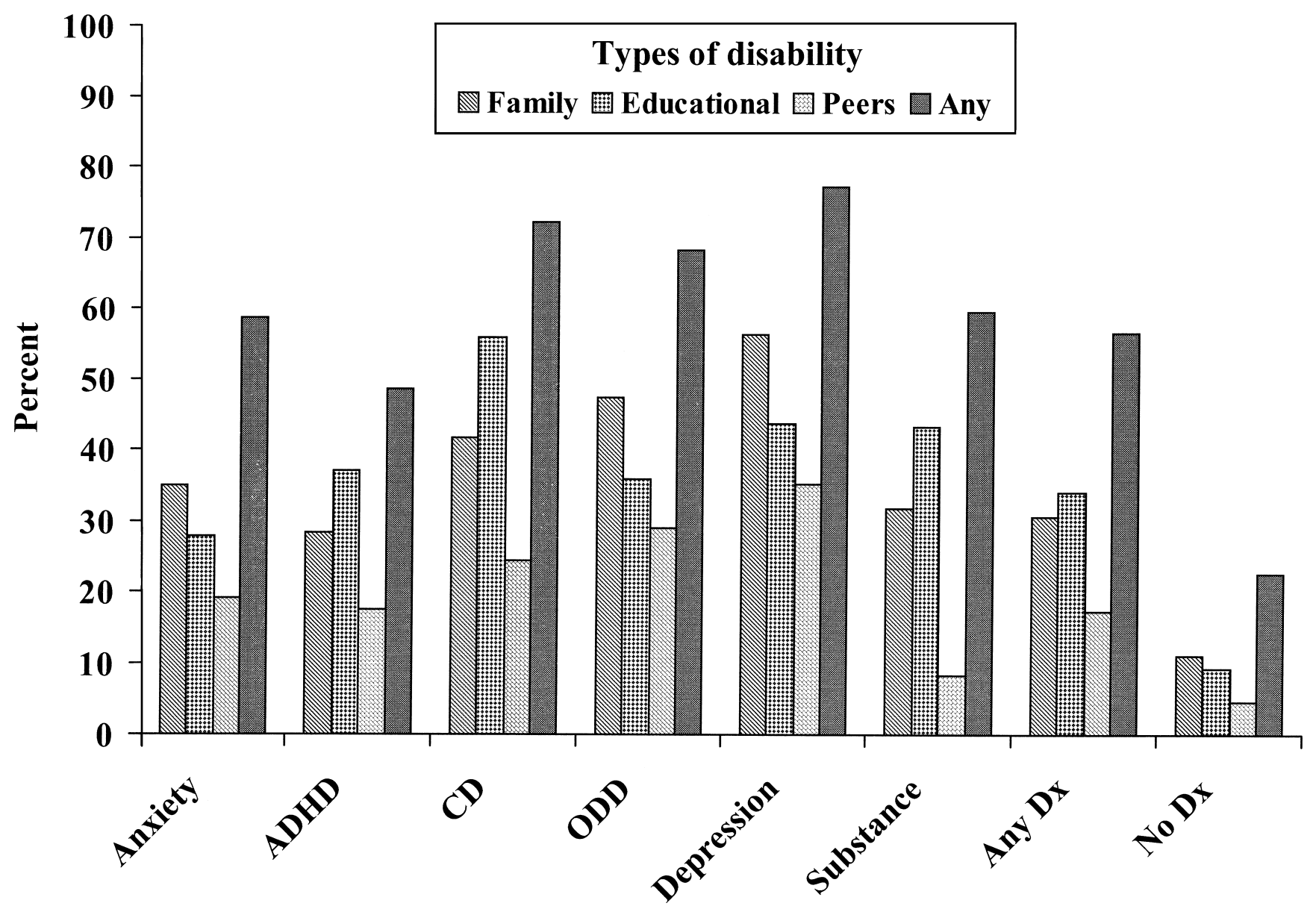

Figure 4. Raw bivariate relationships between diagnoses and disabilities.

Table 6

Effects of Diagnosis, Gender, and Minority Status on Disabilities

\begin{tabular}{|c|c|c|c|c|}
\hline \multirow[b]{2}{*}{ Predictor } & \multicolumn{4}{|c|}{ Area of disability } \\
\hline & $\begin{array}{c}\text { Any } \\
\text { OR }(95 \% \mathrm{CI})\end{array}$ & $\begin{array}{c}\text { Family } \\
\text { OR }(95 \% \mathrm{CI})\end{array}$ & $\begin{array}{c}\text { Educational } \\
\text { OR }(95 \% \mathrm{CI})\end{array}$ & $\begin{array}{c}\text { Peer } \\
\text { OR }(95 \% \text { CI })\end{array}$ \\
\hline Gender & $1.2(0.94-1.6)$ & $0.70 *(0.59-0.97)$ & $2.6^{* * *}(1.9-3.4)$ & $1.1(0.71-1.6)$ \\
\hline Minority status & $1.3(0.94-1.8)$ & $0.68(0.46-1.0)$ & $2.2 * * *(1.5-3.0)$ & $1.4(0.75-2.5)$ \\
\hline Depression & $2.6^{* *}(1.3-5.2)$ & $3.0^{* * *}(1.6-5.6)$ & $2.5^{*}(1.1-5.0)$ & $2.8^{* *}(1.4-5.5)$ \\
\hline Anxiety & $2.7^{* *}(1.4-5.0)$ & $2.0 * *(1.2-3.2)$ & $2.3(0.97-5.3)$ & $1.6(0.77-3.3)$ \\
\hline Substance & $2.7^{* * * *(1.8-4.1)}$ & $2.1 * *(1.3-3.4)$ & $4.0 * * *(2.4-6.6)$ & $0.93(0.51-1.69)$ \\
\hline ODD & $2.8^{* * *}(2.0-4.1)$ & $3.4^{* * *}(2.3-4.8)$ & $2.4 * * *(1.7-3.5)$ & $4.0^{* * *}(2.4-6.6)$ \\
\hline $\mathrm{CD}$ & $2.5^{* * *}(1.6-3.8)$ & $1.8 *(1.03-3.2)$ & $2.9^{* * *}(1.7-4.9)$ & $1.3(0.74-2.4)$ \\
\hline ADHD & $1.1(0.5-2.3)$ & $1.2(0.63-2.2)$ & $2.2 *(1.1-4.5)$ & $1.6(0.92-2.8)$ \\
\hline \multirow[t]{3}{*}{ Minority $\times$ ADHD } & $5.2^{* *}(1.7-16.4)$ & $11.6 *(1.6-86.1)$ & $4.2 *(1.4-13.0)$ & \\
\hline & Majority: 1.1 & Majority: 1.2 & Majority: 2.2 & \\
\hline & Minority: 6.4 & Minority: 17.8 & Minority: 10.3 & \\
\hline \multirow[t]{3}{*}{ Minority $\times$ ODD } & $2.8 *(1.2-6.5)$ & & & \\
\hline & Majority: 2.8 & & & \\
\hline & Minority: 8.3 & & & \\
\hline \multirow[t]{3}{*}{ Minority $\times$ CD } & & $3.8 *(1.3-11.3)$ & & $8.1^{* * *}(2.4-28.1)$ \\
\hline & & Majority: 1.8 & & Majority: 1.3 \\
\hline & & Minority: 7.6 & & Minority: 12.2 \\
\hline
\end{tabular}

very few analogous studies of psychiatric disability. The studies that there are also come to quite different conclusions. Bird and colleagues (1993) reported that the CIS was best represented as a unifactorial scale. John and colleagues (1987) preferred a three-factor solution for the SAICA, whereas Riley and colleagues (1998) refer to an unreported 10-factor solution. Our findings provide support for both Bird's and John's findings. Our factor analyses indicated that a single-factor solution provided a reasonable description of the relationships among different areas of impairment. All the multifactorial solutions were more or less unstable (despite our relatively large samples), but the most satisfactory threefactor solutions broadly indicated that subdomains of school disabilities, family disabilities, and peer disabilities could be distinguished. The content of these three factors 
was quite similar to John's three factors (which were labeled "task performance", "family relations", and "spare time sociability"). Solutions with higher numbers of factors were very unstable, and we certainly found no support for the existence of as many as 10 factors. Beyond this grouping into three rather obvious dimensions, it is notable that there was no evidence for separate factors for socially withdrawn, as opposed to socially disruptive, disability. These two aspects of social disability consistently loaded together within the school, family, and peer dimensions, and still showed no sign of consistent separation even in models with larger numbers of factors.

Overall, boys were slightly more likely to be psychiatrically disabled than girls, but this difference was reduced to nonsignificance when diagnostic status was controlled for. However, boys were much more prone to have school-related disabilities, whereas girls were more likely to have family-related disabilities, even when diagnostic status was controlled. Although a number of studies have suggested that gender may affect the manifestations of some disorders (Andersen \& Teicher, 2000; Arnold, 1996; Compas et al., 1997; Gaub \& Carlson, 1997; Lewinshon, Gotlib, Lewinshon, Seeley, \& Allen, 1998; Schraedley, Gotlib, \& Hayward, 1999; Stewart, Taylor, \& Baker, 1997), and Riley et al. (1998) reported that among young people with emotional and disruptive disorders boys had worse social functioning, we found no interactions between gender and diagnosis in relation to disability, so it appeared that each diagnosis had roughly equal implications for the presence of disability in boys and girls.

Why, then, were there differences in the rates of school and family problems in boys and girls, even when diagnosis was controlled? Part of the answer lies in the fact that many individuals with impairment did not have enough, or the right combinations of, symptoms for a diagnosis (though they were symptomatic). We previously showed that disabled, but undiagnosed, individuals most commonly had subthreshold symptoms of disruptive behavior disorders, and such symptoms are more common in boys than girls. On the other hand, depressive and anxiety symptoms are more common in girls than boys in adolescence, and there were strong associations between depression and anxiety diagnoses and family disability. It seems likely that these associations would extend to subthreshold symptomatology in these areas also, leading to higher proportions of girls having family disability, even when diagnosis was controlled for.

Two minority groups were substantially represented in our sample-American Indians (represented by a $100 \%$ oversample), and African Americans (who were sampled in the same manner as Whites). When combined, these two minority groups constituted $28 \%$ of the sample. Overall, the prevalence of disability was slightly higher in the minority participants ( $32 \%$ vs. $27 \%$ in Whites). This difference was accounted for by school and peer disabilities. There was no difference between minority and majority participants with respect to family disability. When the presence of sufficient symptoms to meet diagnostic criteria for the most common disorders was controlled, minority participants still had twice the odds of having school disability compared with majority participants, while the main effect of peer disabilities was nonsignificant. Minority participants with disruptive diagnoses were much more likely to have a disability than majority participants with such a diagnosis. This effect was most pronounced with respect to ADHD symptoms. However, minority participants with a disruptive behavior disorder were not more symptomatic than majority participants with a disruptive behavior disorder. Minority individuals were more vulnerable to school disabilities at all levels of symptomatology, but more vulnerable to peer or family disability than majority participants only when they had one or other of the disruptive behavior disorders. These findings underscore the ICIDH-2's conceptualization of activity limitations and participation restrictions as being the product not just of the health condition that underlies them, but of the interaction between that health condition and environmental and social factors. Our results can be seen as part of a wider pattern of social disadvantage, which includes the observation that African-American young people are twice as likely as White young people to be arrested for an offense, and three times as likely to end up incarcerated (National Research Council, 2000). These results are unlikely to be due to cultural differences in the perception of disorders or disabilities (Katz \& Kofkin, 1997), or understanding of specific questions (Lin \& Kelsey, 2000), because the interviewers made the judgements about the relationship between symptoms and disability according to rules prescribed in the CAPA glossary, on the basis of descriptions of symptoms and their results provided by the interviewees. Thus respondents were required neither to recognize the presence of disorder, nor to acknowledge disability. They merely had to describe links among emotions, behaviors, and life functions. We determined what was to be considered a symptom or disorder, and what a disability.

Several aspects of the results with respect to particular types of symptomatology bear further attention. The first is that, overall, anxiety was as likely to be disabling as depression, and ODD was as likely to be disabling as CD. The only notable difference between the effects of depression and anxiety was in relation to peer and school disabilities, which were not significantly related to anxiety. On the other hand, there was a strong relationship between ODD and peer disabilities, but no significant relationship between $\mathrm{CD}$ and peer disabilities. ODD was also more strongly related to family disabilities than was CD. It is common to think of anxiety disorders as being less problematic than depressive disorders in children and adolescents, but our data contradict that notion. Similarly, from the perspective of our measures of disability, there is reason to regard ODD as being a more "severe" disorder than CD. Even if this is too extreme an interpretation, our data do not support the notion that ODD is simply an early or minor form of CD. That different patterns of disability were associated with ODD and $\mathrm{CD}$ also tends to contradict the notion that ODD and $C D$ simply represent alternative or successive forms of the same disorder. It is possible that some of these diagnosis-specific effects on disability resulted from psychopathology directly affecting the respondents' perceptions of their limitations and participation restrictions. For instance, perhaps depressed children with perfectly good grades tended to report that their school work had deteriorated. As with the possibility of cultural differences in responding discussed above, we are somewhat protected here by the nature of the evaluations performed, which required that "objective" evidence of disability (such as falling grades) be provided. However, it is possible that some of the diagnosis-specific effects resulted from diagnosis-related reporting biases. 
It may seem surprising that ADHD symptoms were relatively weakly associated with disability, but it is important to bear in mind that the very youngest members of this sample were aged 9 at the first wave of observation. The great bulk of our sample consisted of adolescents, but the DSM-IV ADHD criteria were optimized on clinical samples of younger children, and it is well-recognized that counts of DSM ADHD symptoms fall dramatically in adolescence. Those who still met the DSM-IV symptom criteria in our study, therefore, were not likely to be very similar to the children with ADHD familiar from clinical samples (though they are representative of children of this age who meet ADHD criteria in the general population). In adolescence, many of those who still meet criteria for ADHD also have comorbid diagnoses, and we examined the effects of each diagnosis controlling for the effects of other major diagnoses. Hodges et al. (1999) also found that youth enrolled in the system of care diagnosed as having conduct/oppositional problems or depressed mood were more impaired than those with ADHD.

The presence of potentially problematic substance use also had no effect on the probability of peer disability, though it had marked associations with family and school disabilities (particularly the latter). It seems likely, of course, that problematic substance users had good relationships with deviant peers, and that raises an important question about the measurement of peer disabilities. A notable limitation of our work is that we have no idea what the peers thought of our participant's relationships with them. It is certainly likely that many children would not have wanted to associate with substance-abusing, conduct-disordered individuals, so there is a case to be made for regarding association with deviant peers as a participation restriction in relations with nondeviant peers. We collected no data on the nature of individuals' peer groups, so we could not examine this question directly. However, there is a conceptual issue to be considered here, and that is the extent to which it is acceptable to allow potential causes of health conditions to be regarded as disabilities. Association with deviant peers is widely regarded as being part of the nexus of causal processes leading to and maintaining substance abuse and, just as the ICIDH-2 maintains a clear conceptual boundary between health conditions and disabilities, it is reasonable to try to reduce conflation of the causes and consequences of health conditions. The ICIDH-2 is clearly intended to be a classification of consequences, so from that perspective likely causal factors are better not included in measures of disability. However, the borders between causes and consequences are often poorly drawn as far as psychopathology is concerned, and this issue deserves more attention than it has received so far (Üstun \& Chatterji, 1997).

The differences among the disorders in their associations with our three subareas of disability provide support for the subtyping we derived by factor analysis. Though the psychometric analyses indicated that it would not be unreasonable to collapse all our disability items into a single scale, had we done so we would not have observed these differential diagnostic relationships. Our current attitude to this issue parallels our attitude to the use of diagnosis as a predictor or independent variable. For some purposes an overall measure of the presence of any diagnosis may be useful (for instance in estimating total community need for treatment services). However, in other situations, measures of specific diagnoses (or even symptoms) are required (as for etiological research on depression). Where disability is concerned, sometimes an overall measure is required (perhaps we need to give legislators an estimate of the overall burden of psychiatric disability). However, a more differentiated approach will often be advantageous. For instance, were one to be interested in designing a targeted intervention to reduce school disability in this age range, our data suggest that it would be wise to target individuals with $C D$ and problematic patterns of substance use. However, these would seem to be poor targets for a program aimed at improving peer relationships. At this point we can hardly be said to have firmly established the best method of subdividing disabilities, but we believe that we have provided evidence that there is value in doing so, and hope that others will want to examine these questions further to expand the remarkably small literature on the topic.

There were some notable differences in the patterns of age effects on the specific areas of disability between boys and girls. These differences were superimposed on an overall complex pattern of age effects shared by boys and girls. This pattern, characterized statistically by a cubic relationship between age and disability, applied to the presence of any disability and school disabilities in both boys and girls, and to family disabilities in girls only. These age curves were broadly characterized by an initial drop in the prevalence of disability from age 9 to about age 11 , followed by increases from age 12 to 15 , followed by another drop at age 16 . The exact timing and extent of these changes varied somewhat between genders and areas, but this broad pattern provides a reasonable description of the key effects. One possibility that must be considered is that this may be partly an effect of interview attenuation. In short-term test-retest studies of both questionnaires and interviews it has been repeatedly observed that fewer symptoms are reported at the second interview (Lucas et al., 1999; Piacentini et al., 1999). In the CAPA test-retest study, however, symptom attenuation was seen only for $C D$, and none was found for disability scores. There are few data concerning probable levels of attenuation over periods as long as a year, but attenuation cannot be the whole story here. Since we had an overlapping cohorts design, at many ages two cohorts contributed observations: for instance, the observations at age 11 , where the prevalence of disability was estimated from the first wave of interviews with cohort $\mathrm{A}$ and the third wave of interviews with cohort $\mathrm{B}$. The observations on 13-year-olds were also derived from a combination of first (cohort B) and third interviews (cohort C), but had a much higher value than that observed at age 11. The observations of 15-year-olds were derived from the third interview with cohort $\mathrm{C}$, the fifth wave of interviews with cohort B, and the sixth wave of interviews with cohort A. Despite being completely derived from later wave interviews, this was the set of observations with the highest prevalence of disability. It is possible that an interview attenuation effect could have reduced the apparent size of some of the changes with age, but it could not have accounted for the observed results.

The overall prevalence of any of 29 disorders across all waves of the data was $12.9 \%$. This figure included only diagnoses that met all DSM-IV diagnostic criteria (including the DSM-IV "distress" or "impairment" criteria). For depressive or anxiety diagnoses, the "distress" criterion was met, by definition, because depressed mood, worrying and anxious affect are all defined in the CAPA 
glossary as having to be unpleasant mood states; non distressful phenomena are not coded even as symptoms. However, no such "distress" criterion is included for rating symptoms of disorders such as ODD or CD. Indeed, we cannot see the logic of asking children questions about whether their lying, cheating, and stealing "bothers them". Of the children who met full DSM-IV criteria for a diagnosis, only $58.2 \%$ were disabled. Conversely, of the $27 \%$ of the population with psychiatric disability, $72.2 \%$ did not meet full DSM-IV criteria for a diagnosis (other than a possible NOS diagnosis). We have shown before that there is good reason to regard the latter group as having significant psychiatric disorders (Angold et al., 1999), and suggested that such individuals be regarded as having "NOS" conditions. Does this suggestion violate the ICIDH-2's conceptual separation of the health condition from the disability it causes? On the face of it it appears to, but, as we noted in the Introduction, most health conditions have to be inferred from the presence of the impairments of structure and function that they cause. Here we see that many child and adolescent psychiatry disorders must be inferred from the activity limitations and participation restrictions they cause. When such limitations and restrictions are observed to have resulted from psychiatric symptoms it is entirely reasonably to infer that a child has a psychiatric condition. Note the italics here. We are not suggesting that all problems in psychosocial functioning should be considered to be psychiatric disorders; only those associated with recognized psychiatric symptoms. The problem is that such conditions do not meet criteria for the definition of any clearly defined health condition -we know the child has something, but we do not know exactly what. What we need are better definitions of those health conditions so that we can define them in the future without regard to the disabilities they cause. That is a very different conceptual position from requiring in the definition of psychiatric disorders in general that they must generate disability. The former position recognizes our ignorance and suggests a strategy for overcoming it, whereas the latter tends to hide weakness in our nosologies by muddying the conceptual waters. So far child and adolescent psychiatric epidemiology has paid little attention to its role in developing nosology, having only recently come to grips with developing methods for identifying disorders that conform to the definitions of "well-defined" DSM or ICD disorders. However, the definitions of those disorders have been based on clinical experience and research, and clinical samples are very biased samples of the distribution of psychiatric symptomatology (Costello \& Janiszewski, 1990). We believe that there is a real need for more epidemiological attention to be paid to the implications of the existence of a substantial group of conditions that we cannot currently define adequately.

From a developmental perspective, it is not surprising that we find ourselves in this position. Most disorders do not spring up instantaneously and simultaneously cause disability (either in psychiatry or the rest of medicine). Rather it is to expected that the development of many psychiatric disorders will be a long-drawn-out process, and that at some point in that process, in some individuals, disability will become apparent. Pickles et al. (in press) showed that across a range of disorders there was a progressive increase in the probability of disability as symptom levels increased, but in no case was there any evidence that achieving the DSM-IV or ICD-10 criterial symptom thresholds for the disorders was associated with a notable jump in levels of disability. This innovative study points up only too clearly how little we know about the interplay between psychiatric symptomatology and disability. In this field we have expended an enormous amount of energy in developing rules for defining disorders on the symptom level, but have not even attempted to develop a consensus about the measurement of disability, even though it now plays a central role in the definition of health conditions in the DSM-IV. The good news is that there are many epidemiological studies of children and adolescents that have collected both symptom and disability data (like ours) and that offer the chance to address key questions about the relationships among symptoms, diagnoses, and disabilities immediately. Our sample was representative of predominantly rural children and adolescents aged 9-16, and we wonder, for instance, whether similar findings would result from examination of inner-city samples, and in younger children and old teenagers. We hope that our work will provide a stimulus to investigations of questions such as these.

Acknowledgements-This work was supported by NIMH Center funding (MH-57761), NIMH grant MH-48085, NIDA grant DA11301, and DGICYT PM98-173 and Programa Sectorial de Ayudas de Movilidad de Profesorado Universitario e Investigadores from the Ministry of Education and Culture (Spain).

\section{References}

American Psychiatric Association. (1994). Diagnostic and statistical manual of mental disorders fourth edition (DSM-IV). Washington, DC; American Psychiatric Press.

Andersen, S. L., \& Teicher, M. H. (2000). Sex differences in dopamine receptors and their relevance to ADHD. Neuroscience and Biobehavioral Reviews, 24, 137-142.

Angold, A., \& Costello, E. J. (1995). A test-retest reliability study of child-reported psychiatric symptoms and diagnoses using the Child and Adolescent Psychiatric Assessment (CAPA-C). Psychological Medicine, 25, 755-762.

Angold, A., \& Costello, E. J. (2000). The Child and Adolescent Psychiatric Assessment (CAPA). Journal of the American Academy of Child and Adolescent Psychiatry, 39, 39-48.

Angold, A., Costello, E. J., Farmer, E. M. Z., Burns, B. J., \& Erkanli, A. (1999). Impaired but undiagnosed. Journal of the American Academy of Child and Adolescent Psychiatry, 38, 129-137.

Angold, A., Erkanli, A., Costello, E. J., \& Rutter, M. (1996). Precision, reliability and accuracy in the dating of symptom onsets in child and adolescent psychopathology. Journal of Child Psychology and Psychiatry, 37, 657-664.

Angold, A., Prendergast, M., Cox, A., Harrington, R., Simonoff, E., \& Rutter, M. (1995). The Child and Adolescent Psychiatric Assessment (CAPA). Psychological Medicine, 25, 739-753.

Arnold, L. E. (1996). Sex differences in ADHD: Conference summary. Journal of Abnormal Child Psychology, 24, 555-569.

Bird, H. R., Canino, G., Rubio-Stipec, M., \& Ribera, J. C. (1987). Further measures of the psychometric properties of the Children's Global Assessment Scale. Archives of General Psychiatry, 44, 821-824.

Bird, H. R., Shaffer, D., Fisher, P. W., Gould, M. S., Staghezza, B., Chen, J. Y., \& Hoven, C. (1993). The Columbia Impairment Scale (CIS): Pilot findings on a measure of global impairment for children and adolescents. International Journal of Methods in Psychiatric Research, 3, 167-176. 
Bird, H. R., Yager, T. J., Staghezza, B., Gould, M. S., Canino, G., \& Rubio-Stipec, M. (1990). Impairment in the epidemiological measurement of childhood psychopathology in the community. Journal of the American Academy of Child and Adolescent Psychiatry, 29, 796-803.

Canino, G., Costello, E. J., \& Angold, A. (1999). Assessing functional impairment for child mental health services research: A review of measures. Journal of Mental Health Services Research, 1, 93-108.

Compas, B. E., Oppedisano, G., Connor, J. K., Gerhardt, C. A., Hinden, B. R., Achenbach, T. M., \& Hammen, C. (1997). Gender differences in depressive symptoms in adolescence: Comparison of national samples of clinically referred and nonreferred youths. Journal of Consulting and Clinical Psychology, 65, 617-626.

Costello, E. J., Angold, A., Burns, B. J., Stangl, D. K., Tweed, D. L., Erkanli, A., \& Worthman, C. M. (1996). The Great Smoky Mountains Study of Youth: Goals, designs, methods, and the prevalence of DSM-III-R disorders. Archives of General Psychiatry, 53, 1129-1136.

Costello, E. J., Angold, A., \& Keeler, G. P. (1999). Adolescent outcomes of childhood disorders: The consequences of severity and impairment. Journal of the American Academy of Child and Adolescent Psychiatry, 38, 121-128.

Costello, E. J., Angold, A., March, J., \& Fairbank, J. (1998). Life events and post-traumatic stress: The development of a new measure for children and adolescents. Psychological Medicine, 28, 1275-1288.

Costello, E. J., Angold, A., Messer, S. C., \& Farmer, E. M. Z. (1996). Symptoms and impairment: Serious emotional disturbance in the Great Smoky Mountains study. In 9th Annual Research Conference, (February 26-28). Tampa, FL: The Research and Training Center for Children's Mental Health.

Costello, E. J., \& Janiszewski, S. (1990). Who gets treated? Factors associated with referral in children with psychiatric disorders. Acta Psychiatrica Scandinavica, 81, 523-529.

Diggle, P. J., Liang, K. Y., \& Zeger, S. L. (1994). Analysis of longitudinal data. Oxford: Clarendon Press.

Ezpeleta, L., Granero, R., de la Osa, N., \& Guillamon, N. (2000). Predictors of functional impairment in children and adolescents. Journal of Child Psychology and Psychiatry, 41, 793-801.

Gaub, M., \& Carlson, C. L. (1997). Gender differences in ADHD: A meta-analysis and critical review. Journal of the American Academy of Child and Adolescent Psychiatry, 36, 1036-1045.

Green, B., Shirk, S., Hanze, D., \& Wasntrath, J. (1994). The children's global assessment scale in clinical practice: An empirical evaluation. Journal of the American Academy of Child and Adolescent Psychiatry, 33, 1158-1164.

Gureje, O., \& Omigbodun, O. O. (1995). Children with mental disorders in primary care: Functional status and risk factors. Acta Psychiatrica Scandinavica, 92, 310-314.

Hodges, K., \& Cheong-Seok, K. (2000). Psychometric study of the child and adolescent functional assessment scale: Prediction of contact with the law and poor school attendance. Journal of Abnormal Child Psychology, 28, 287-297.

Hodges, K., Doucette-Gates, A., \& Liao, Q. (1999). The relationship between the Child and Adolescent Functional Assessment Scale (CAFAS) and indicators of functioning. Journal of Child and Family Studies, 8, 109-122.

Hodges, K., \& Wong, M. M. (1996). Psychometric characteristics of a multidimensional measure to assess impairment: The Child and Adolescent Functional Assessment Scale. Journal of Child Family Studies, 5, 445-467.

Hodges, K., \& Wong, M. M. (1997). Use of the child and adolescent functional assessment scale to predict service utilization and cost. Journal of Mental Health Administration, 24, 278-290.

Hodges, K., Wong, M. M., \& Latessa, M. (1998). Use of the child and adolescent functional assessment scale (CAFAS) as an outcome measure in clinical settings. Journal of Behavioral Health Services and Research, 25, 325-336.
John, K., Davis, G. D., Prusoff, B. A., \& Warner, V. (1987). The Social Adjustment Inventory for Children and Adolescents (SAICA): Testing of a new semistructured interview. Journal of the American Academy of Child and Adolescent Psychiatry, 26, 898-911.

Katz, P. A., \& Kofkin, J. A. (1997). Race, gender and young children. In S. S. Luthar, J. A. Burack, D. Ciccheti, \& J. R. Weisz (Eds.), Developmental psychopathology (pp. 51-74). New York: Cambridge University Press.

Lavigne, J. V., Binns, H. J., Arend, R., Rosenbaum, D., Christoffel, K. K., Hayford, J. R., \& Gibbons, R. D. (1998). Psychopathology and health care use among preschool children: A retrospective analysis. Journal of the American Academy of Child and Adolescent Psychiatry, 37, 262-270.

Lewinsohn, P. M., Gotlib, I. H., Lewinsohn, M., Seeley, J. R., \& Allen, N. B. (1998). Gender differences in anxiety disorders and anxiety symptoms in adolescents. Journal of Abnormal Psychology, 107, 109-117.

Lin, S. S., \& Kelsey, J. L. (2000). Use of race and ethnicity in epidemiologic research: Concepts, methodological issues, and suggestions for research. Epidemiologic Reviews, 22, 187-202.

Lucas, C. P., Fisher, P., Piacentini, J., Zhang, H., Jensen, P. S., Shaffer, D., Dulcan, M., Schwab-Stone, M., Regier, D., \& Canino, G. (1999). Features of interview questions associated with attenuation of symptom reports. Journal of Abnormal Child Psychology, 27, 429-437.

Lyons, J. S., O'Mahoney, M., Miller, S. I., Neme, J., Kabat, J., \& Miller, F. (1997). Predicting readmission to the psychiatric hospital in a managed care environment: Implications for quality indicators. American Journal of Psychiatry, 154, 337-340.

McArdle, P., \& Gillett, T. (1997). Psychiatric in-patient treatment for children and adolescents in the UK: Criteria for admission. Israel Journal of Psychiatry and Related Sciences, 34, 195-199.

Murray, C. J. L., \& López, A. D. (1996). The global burden of disease. Geneva, Switzerland: World Health Organization.

Muthén, B. (1978). Contributions to factor analysis of dichotomous variables. Psychometrika, 43, 551-560.

Muthén, B. (1983). Latent variable structural equation modeling with categorical data. Journal of Econometrics, 22, 43-65.

Muthén, B. (1984). A general structural equation model with dichotomous, ordered categorical and continuous latent variable indicators. Psychometrika, 49, 115-132.

Muthén, B. (1989). Dichotomous factor analysis of symptom data. Sociological Methods and Research, 18, 19-65.

National Research Council. (2000). Juvenile crime, juvenile justice. Panel on Juvenile Crime: Prevention, treatment, and control, Committee on Law and Justice, Commission on Behavioral and Social Sciences and Education. Washington, DC: National Academy Press.

Piacentini, J., Roper, M., Jensen, P., Lucas, C., Fisher, P., Bird, H., Bourdon, K., Schwab-Stone, M., Rubio-Stipec, M., Davies, M., \& Dulcan, M. (1999). Informant-based determinants of symptom attenuation in structured child psychiatric interviews. Journal of Abnormal Child Psychology, 27, 417-428.

Pickles, A., Dunn, G., \& Vazquez-Barquero, J. (1995). Screening for stratification in two-phase ('two-stage') epidemiological surveys. Statistical Methods in Medical Research, 4, 73-89.

Pickles, A., Rowe, R., Simonoff, E., Foley, D., Rutter, M., \& Silberg, J. (in press). Child psychiatric symptoms and psychosocial impairment: Relationship and prognostic significance. British Journal of Psychiatry.

Riley, A. W., Ensminger, M. E., Green, B., \& Kang, M. (1998). Social role functioning by adolescents with psychiatric disorders. Journal of the American Academy of Child and Adolescent Psychiatry, 37, 620-628.

Schraedley, P. K., Gotlib, I. H., \& Hayward, C. (1999). Gender 
differences in correlates of depressive symptoms in adolescents. Journal of Adolescent Health, 25, 98-108.

Settertobulte, W., \& Kolip, P. (1997). Gender-specific factors in the utilization of medical services during adolescence. Journal of Adolescence, 20, 121-132.

Shaffer, D., Fisher, P., Lucas, C. P., Dulcan, M. K., \& SchwabStone, M. E. (2000). NIMH diagnostic interview schedule for children version IV (NIMH DISC-IV): Description, differences from previous versions, and reliability of some common diagnoses. Journal of the American Academy of Child and Adolescent Psychiatry, 39, 28-38.

Shaffer, D., Gould, M. S., Brasic, J., Ambrosini, P., Fisher, P. Bird, H., \& Aluwahlia, S. (1983). A Children's Global Assessment Scale (CGAS). Archives of General Psychiatry, 40, 1228-1231.

Spitzer, R. L., \& Wakefield, J. (1999). DSM-IV diagnostic criterion for clinical significance: Does it help solve the false positive problems? American Journal of Psychiatry, 156, $1856-1864$

Stewart, S. H., Taylor, S., \& Baker, J. M. (1997). Gender differences in dimensions of anxiety sensitivity. Journal of Anxiety Disorders, 11, 179-200.

Üstun, B., \& Chatterji, S. (1997). Editorial: Measuring functioning and disability - a common framework. International Journal of Methods in Psychiatric Research, 7, 79-83.
Verhulst, F. C., Akkerhuis, G. W., \& Althaus, M. (1985). Mental health in Dutch children: I. A cross-cultural comparison. Acta Psychiatrica Scandinavica, 72, 1-108.

Verhulst, F. C., Mart, L., Eussen, J. M., Guy, F. M., Berden, G., Sanders-Woudstra, J., \& Van Der Ende, J. (1993). Pathways of problem behaviors from childhood to adolescence. Journal of the American Academy of Child and Adolescent Psychiatry, 32, 388-396.

Wakefield, J. C. (1997). When is development disordered? Developmental psychopathology and the harmful dysfunction analysis of mental disorders. Development and Psychopathology, 9, 269-290.

World Health Organization. (1993). The ICD-10 classification of mental and behavioural disorders: Diagnostic criteria for research. Geneva, Switzerland: Author.

World Health Organization. (1994). ICIDH-2: International classification of functioning and disability. Beta-2 draft, Long version. Geneva, Switzerland: Author.

World Health Organization. (2000). ICIDH-2: International classification of functioning, disability and health. Pre-final draft, Full version. Geneva, Switzerland: Author.

Manuscript accepted 4 June 2001 